\title{
Intellect and intuition
}

\author{
An Idealist View of Life \\ by Sarvepalli Radhakrishnan \\ George Allen and Unwin: 1932
}

\section{Gautam R. Desiraju}

Sarvepalli Radhakrishnan was in his time the most renowned interpreter of Indian philosophy to an international audience. In An Idealist View of Life, based on the Hibbert lectures he delivered at the universities of London and Manchester in 1929-30, he presents his thesis on the nature and meaning of life.

The book weaves a spiritual approach through its metaphysical argument, also adopting a scientific attitude, to produce a bold view of creative thinking. Radhakrishnan exposes the inadequacy of existing religions and contrasts them with science, which "demands induction from facts and not deduction from dogmas". Speaking amid the gathering storm of the impending war in Europe, he is disappointed by the moral inadequacy and destructive political consequences of established faiths, and states that "nothing is as hostile to religions as other religions". If religion is ineffective, the new gods of atheism, agnosticism and authoritarianism are equally without worth, and he describes the modish sceptic as someone for whom nothing is serious and who "drifts along confusedly, hoping for the best, expecting little and believing in nothing very much". This is not an inaccurate description of many scientists today, for whom the deeper meaning of science remains elusive in an ever-changing yet constant world.

According to Radhakrishnan, there are two forms of knowledge: intellectual and intuitive. Intellectual knowledge lies at the core of Western systems of philosophy and is based on critical analysis and logic. If all knowledge were purely intellectual, reason alone would suffice, eventually leading to hard-core reductionism. However, Eastern systems of philosophy, particularly Hinduism, believe in a higher form of knowledge built on intuition. Intuition is essentially synthesis, which in turn follows naturally from Hindu ideas of monism. According to advaitic (non-dualistic) doctrine, one who knows the Absolute becomes the Absolute. Accordingly, ignorance of this knowledge is the root of all trouble.

It is understandable thus far. But
Radhakrishnan then claims that the true test of knowledge is certainty, which is a characteristic of intuitive thinking, rather than communicability, which characterizes intellectual knowledge. He then argues that intuition does not oppose intellect but rather lies beyond it. In other words, intuitive knowledge, although it does not contradict the necessity of reason, questions the sufficiency of reason. Intuition is not illogical but super-logical. In summary, both intellect

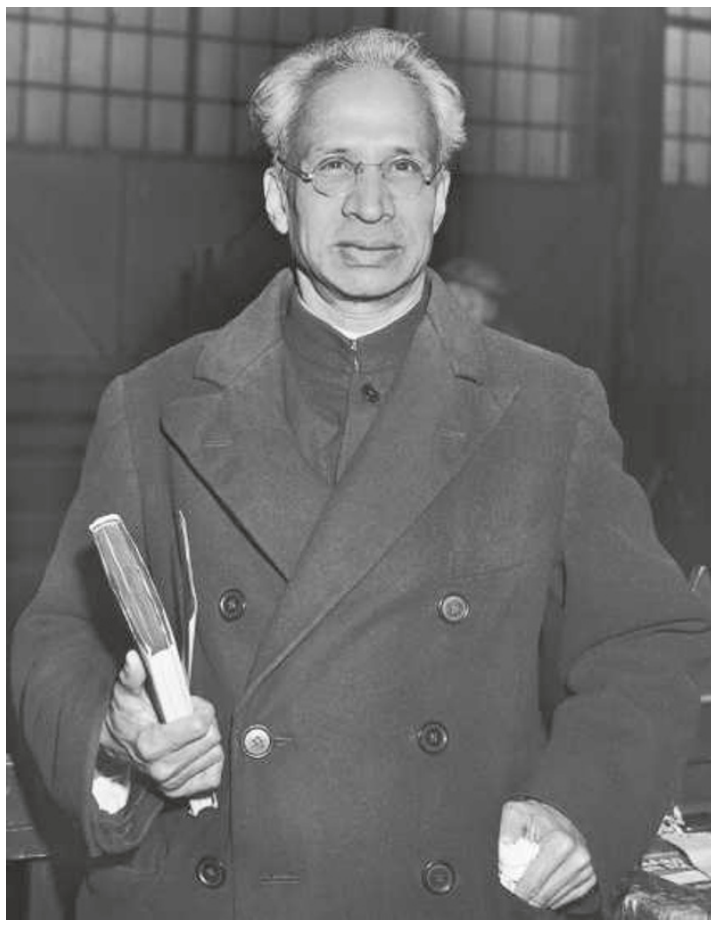

Sarvepalli Radhakrishnan combined spirituality and science.

and intuition must be synergized in the quest for the nature of ultimate reality.

Addressing scientific issues,

Radhakrishnan argues that "great scientific discoveries are due to the inventive genius of creative thinkers", intuitive thinking being as relevant to science as it is to the arts. Consider, for example, Faraday's discoveries, Mendeleev's periodic table, Kekulé's postulation of the cyclic structure for benzene, or the way in which Crick and Watson unravelled the double-helix structure of DNA.

Several hypotheses in Radhakrishnan's book are worthy of close attention from scientists. First, he says that great intuition arises from a bedrock of rationality. Next, when the big discovery is made, there is enough room for the readjustment and reinterpretation of partial and incomplete concepts and data that preceded the discovery. This readjustment is so simple, says Radhakrishnan, that when full scientific insight is obtained it escapes notice, allowing one to imagine that the process of discovery arose entirely from intellectual thinking. Finally, instinctive thinking is not easily communicable - so when the discovery is discussed, it appears to have arisen from rational thought. The lines between discovery and proof are now blurred, resulting in an erroneous simplification of the deeper movements of thought.

There is much to commend this approach to scientists today, given the increasing complexity inherent in contemporary scientific problems. The coming century will see an intensive study of emergent phenomena such as the prediction of crystal structures, protein folding, fractals and monsoon forecasting. The answers to these difficult questions may not be found in a single model of complexity, such as cellular automata. Eventually, we would even like to examine the differences between life and non-life in, say, chemical terms. Subjects such as physics and chemistry are already redefining their goals to study more complex biological phenomena, with modern chemical biology being a pertinent example of this trend.

As the natural sciences move towards the social sciences and less precise forms of knowledge, there is a real need for inspired intuition, not as a substitute for thought but as a challenge to intelligence. An intuitive and holistic grasp of the situation is required. What we need is not faster computers, but faster minds.

The final section of the book seamlessly synthesizes the role of intuition in the cognitive, aesthetic and ethical endeavours of humankind. Recognizing these efforts as varied facets of human expression, Radhakrishnan opines that only religion based on spiritual values can completely encapsulate the human spirit. At a time when religious fundamentalism threatens the stability of the world, there is an urgent need for intuitive and inquiring scientists to contemplate the eternity between the atom and the Absolute. As Radhakrishnan says: "Real heroes are religious in a true sense in that they have broken down the barriers between the individual and the universal."

Gautam R. Desiraju is in the School of Chemistry, University of Hyderabad, Hyderabad 500 046, India. 